5. Boardman A. Pioneers in metamaterials: John Pendry and Victor Veselago / A. Boardman// Journal of optics. - 2011. - №2. - P.1-6. doi : 10.1088/2040$8978 / 13 / 2 / 020401$

6. Negative refractive index and acoustic superlens from multiple scattering in single negative metamaterials / Nadège Kaina, Fabrice Lemoult, Mathias Fink et al. // Nature - 2015. - №7567. - p.77-81. doi : 10.1038/nature14678

7. Учёные научились «закручивать» акустические волны, для которых использовались специальные метаматериалы: [Електронний ресурс] // Scientific World - научно-информационный журнал. - Режим доступу : http://sciworld.ru/technics/3051-uchenye-nauchilis-zakruchivat-akusticheskie-volny-dlyakotoryh-ispolzovalis-specialnye-metamaterialy.html

8. New Metamaterial Manipulates Sound to Improve Acoustic Imaging : [Електронний ресурс] // NC STATE NEWS. - Режим доступу : https://news.ncsu.edu/2015/12/jing-hm-acoustic-2015/. doi

10.1103/PhysRevLett.115.254301

9. Broadband Acoustic Hyperbolic Metamaterial / Chen Shen, Yangbo Xie, Ni Sui et al. // Physical Review Letters - 2015. - №25. - p.1-5. doi : 10.1103/PhysRevLett.115.254301

10. Ultra-thin metamaterial for perfect and omnidirectional sound absorption / Noé Jiménez, Weichun Huang, Vicent Romero-García et al. // Applied Physics Letters - 2016 - №12. - pp 121902. doi : 10.1063/1.4962328

11. Acoustic metamaterial panel absorbs low-frequency sound : [Електронний pecypc] // PHYSORG. - Режим доступу : https://phys.org/news/2016-09-acousticmetamaterial-panel-absorbs-low-frequency.html\#j $\mathrm{Cp}$

Стаття відправлена: 22.05.2017 г.

(C) Копитько Ю. С.

\title{
ЦИТ: иа217-034
}

DOI: 10.21893/2415-7538.2017-06-1-034

УДК 534.75

ИСПОЛЬЗОВАНИЕ МОДЕЛИ СРЕДНЕГО УХА ЧЕЛОВЕКА НА ОСНОВЕ СВЯЗАННЫХ КОНТУРОВ ДЛЯ ОБРАБОТКИ РЕЗУЛЬТАТОВ АКУСТИЧЕСКОЙ МНОГО ЧАСТОТНОЙ ИМПЕДАНСОМЕТРИИ

Киевский политехнический институт им. И. Сикорского, г. Киев, просп. Победы 37, 03056

Damarad A.V.

USE OF THE HUMAN MIDDLE EAR MODEL ON THE BASIS OF RELATED CONTOURS FOR PROCESSING THE RESULTS OF ACOUSTIC MULTI-FREQUENCY IMPEDANCESOMETRY NTUU «Igor Sikorsky Kiev Polytechnic Institute», Kiev, ave. Peremohy 37, 03056

Аннотация. В работе рассматривается метод диагностики слуха человека на основе многочастной импедансометрии среднего уха человека. 
Анализируется математическая модель среднего уха на основе связанных контуров для исследования функичи евстахиевой трубы.

Ключевые слова: среднее ухо, импедансометрия, тимпанометрия, параметр нормы.

Abstract. This paper considers a method of diagnostics of a human hearing based on the multi-part impedanceometry of the human's middle ear. Mathematical model of the middle ear on the basis of related contours were analyzed for research of the function of the Eustachian tube.

Key words: middle ear, impedanceometry, tympanometry, parameter of the norm.

\section{Вступление}

На сегодняшний день, одной из актуальных проблем является снижение слуха, которое всё чаще беспокоит не только людей пожилого возраста, но и новорождённых. Диагностика слуха у детей - одна из наиболее сложных и актуальных задач современной сурдологии.

Целью данной работы является обоснование выбора многочастотной импедансометрии как одного из основных методов исследования функции среднего уха. Для достижения поставленной цели была кратко рассмотрена анатомия евстахиевой трубы, так же была рассмотрена математическая модель среднего уха для дальнейшей интерпретации результатов многочастной тимпанометрии.

\section{Многочастотная импедансометрия}

Евстахиева труба представляет собой трубку, которая соединяет носоглотку и среднее ухо, и является важным элементом слуховой системы. До сих пор евстахиева труба - мало изученный орган и является предметом исследований, о чём свидетельствуют современные публикации [1-3]. Одним из основных методов ее объективного исследования является метод акустической импедансометрии. Суть метода заключается в измерении модуля акустического сопротивления $Z_{a}$ (импеданса) среднего уха, обусловленного изменениями относительно давления воздуха в герметично закрытом наружном слуховом проходе (НСП) [5]. Стандартной методикой измерения акустического импеданса уха является тимпанометрия - измерение эквивалентного объема в зависимости от относительного давления в НСП, создаваемого пневмосистемой импедансометра [5].

Воспользовавшись методом электромеханических и электроакустических аналогий для расчета среднего уха [6], получим, что подвижная система барабанной перепонки и слуховых косточек ведет себя как последовательный резонансный контур, а евстахиевой трубы и барабанной полости, является элементом связи - как параллельный. Система связанных контуров характеризуется так называемым фактором связи:

$$
A=k_{36} \cdot Q \text {, }
$$

и имеет 2 собственные частоты, где $k_{\text {зв }}$ - коэффициент связи; $Q-$ добротность системы. Условие $A=1$ является условием оптимизации системы на максимум ширины полосы пропускания уха в речевом диапазоне частот $500 \div 4000$ Гц [5]. 
Стандартная частота зондового сигнала в многочастотном импедансометре - 226, 660 или 800 и 1000 Гц.

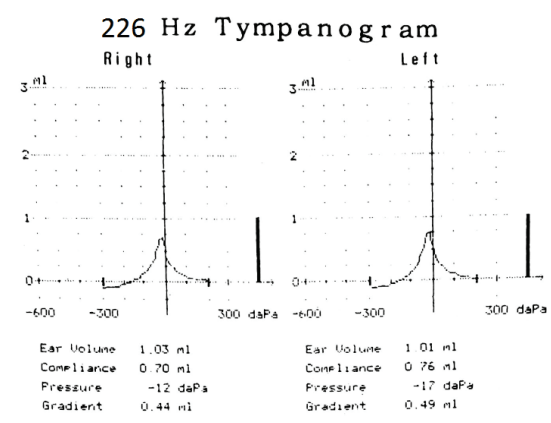

a

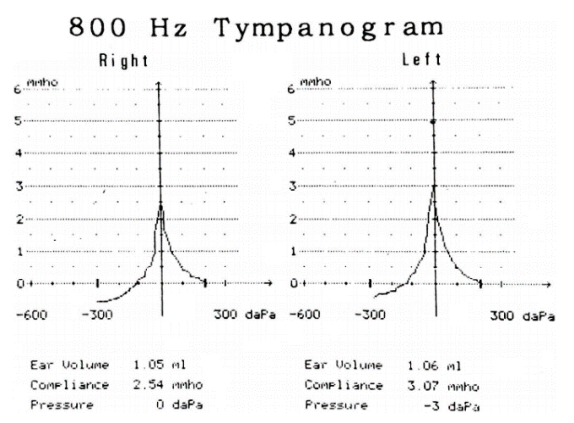

6

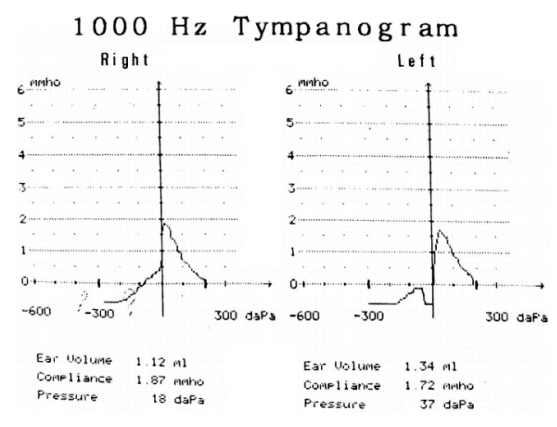

B

Рис. 1. Тимпанограммы правого и левого уха, полученые на частотах: a - 226 Гц; б - 800 Гц; в - 1000 Гц

На рис.1 приведены тимпанограммы правого и левого уха, полученные на частотах 226, 800 и 1000 Гц с помощью клинического ушного импедансометра. Согласно классификации Джегера, тимпанограммы, которые наблюдаются при 226 Гц, в которых максимум отмечается при давлении в ушной полости, равном атмосферному, характерны как для нормального состояния системы среднего уха, так и для отосклеротичного анализа стремени [6-7].

Считается, что со значениями эквивалентного объема величина модуля акустического импеданса связана соотношением:

$$
Z_{a}=\sqrt{R_{a}^{2}+\left(\omega \cdot m_{a . \kappa}-\frac{1}{\omega \cdot C_{a . б . n}}\right)^{2}}=\frac{\rho \cdot c_{0}^{2}}{\omega \cdot V(\omega)}
$$

где $C_{a . б . n}-$ акустическая гибкость барабанной перепонки; $m_{a . \kappa}-$ масса слуховых косточек среднего уха; $R_{a}=Z_{a}\left(f_{p}\right)=\frac{\rho \cdot c_{0}^{2}}{\omega_{p} \cdot V\left(f_{p}\right)}-$ акустическое сопротивление потерь в результате передачи звуковой энергии через цепь слуховых косточек во внутреннее ухо; $\omega_{p}=\frac{1}{\sqrt{m_{a . \kappa} \cdot C_{a . \sigma . n}}}-$ резонансная частота колебаний барабанной перепонки при $\Delta p_{c m}=0 ; \rho=1,2 \frac{\text { кГ }}{\mathrm{M}^{3}}, c_{0}=340 \frac{\mathrm{M}}{\mathrm{c}}-$ плотность воздуха и скорость звука в нем; $V(\omega)$ - эквивалентный объём среднего уха [7].

Выражение (2) представляет собой систему трех нелинейных уравнений с тремя неизвестными $m_{a . \kappa}, C_{a . б . n}, R_{a}$ или $f_{p}, C_{a . б . n}, R_{a}$. Нахождение их значительно упрощается, если учесть, что $R_{a}$ может быть определено по $V_{\max }(800)$ при $\Delta p_{c m} \neq 0$ по формуле $R_{a}=\frac{\rho \cdot c_{0}^{2}}{2 \cdot \pi \cdot 800 \cdot V_{\max }(800)}$. Получаем [7]: 


$$
V(f)=\frac{\frac{800}{f} \cdot V_{\max }(800)}{\sqrt{1+\left[\frac{800}{f} \cdot \frac{V_{\max }(800)}{V_{\sigma . n}} \cdot\left(1-\frac{f^{2}}{f_{p}^{2}}\right)\right]^{2}}},
$$

где $V_{\sigma . n}-$ эквивалентный объем барабанной перепонки. Подставляя сюда $V(226)=0,7 \mathrm{~cm}^{3}, V(1000)=1,87 \mathrm{~cm}^{3}$ и $V_{\max }(800)=2,54 \mathrm{~cm}^{3}$ для правого уха и $V(226)=0,76 \mathrm{~cm}^{3}, \quad V(1000)=1,72 \mathrm{~cm}^{3} \quad$ и $V_{\max }(800)=3,07 \mathrm{~cm}^{3}$ для левого уха получим систему из двух уравнений для двух неизвестных $f_{p}$ и $V_{6 . n}$, решение которой дает: $f_{p}=937,3$ Гц и $V_{\sigma . n}=0,661 \mathrm{~cm}^{3}$ для правого уха, $f_{p}=878,7$ Гц и $V_{6 . n}=0,735 \mathrm{~cm}^{3}$ для левого уха. Систему уравнений (2) можно решить приближенно с помощью программных средств MatLab. Получаем: для правого уха $\quad R_{a}=7,4999 \cdot 10^{6} \frac{\mathrm{\kappa} \Gamma}{\mathrm{M}^{4} \mathrm{c}}, \quad m_{a . \kappa}=6,8116 \cdot 10^{3} \frac{\kappa \Gamma}{\mathrm{M}^{4}}, \quad C_{a . \sigma . n}=4,7255 \cdot 10^{-12} \frac{\mathrm{m}^{3}}{\mathrm{H}}$, $f_{p}=887,1015$ Гц; для левого уха $R_{a}=7,1301 \cdot 10^{6} \frac{\kappa \Gamma}{\mathrm{M}^{4} \mathrm{c}}, m_{a . \kappa}=6,655 \cdot 10^{3} \frac{\kappa \Gamma}{\mathrm{M}^{4}}$, $C_{\text {a.б.n }}=5,1108 \cdot 10^{-12} \frac{\mathrm{M}^{3}}{\mathrm{H}}, f_{p}=862,9832$ Гц.

Эквивалентный объем барабанной перепонки: для правого уха $V_{\text {б.n }}=\rho \cdot c_{0}^{2} \cdot C_{a . \text {..n }}=0,6555 \mathrm{~cm}^{3}, \quad V\left(f_{p}\right)=\frac{\rho \cdot c_{0}^{2}}{\omega_{p} \cdot R_{a}}=\frac{\rho \cdot c_{0}^{2}}{2 \cdot \pi \cdot f_{p} \cdot R_{a}}=3,3184 \mathrm{~cm}^{3} ; \quad$ для левого уха $V_{\sigma . n}=0,7089 \mathrm{~cm}^{3}, V\left(f_{p}\right)=3,5881 \mathrm{~cm}^{3}$.

Подстановка значений эквивалентного объема в выражение параметра нормы дает [7]: для правого уха $A=\frac{V\left(f_{p}\right)}{V_{\sigma . n}} \cdot \frac{1}{\sqrt{1+V_{\tilde{\sigma . n o n}} / V_{\sigma . n}}}=3,2863$; для левого уха $A=3,3595$, где $V_{\text {б.лол }}=0,9 \mathrm{~cm}^{3}$.

Акустический импеданс воздуха в площади барабанной перепонки: для правого уха $Z_{\text {в.a }}=\frac{\rho \cdot c_{0}}{S_{6 . n}}=1,2931 \cdot 10^{6} \frac{\text { кг }}{\mathrm{M}^{4} \mathrm{c}}$; для левого уха $Z_{6 . a}=1,2293 \cdot 10^{6} \frac{\mathrm{\kappa г}}{\mathrm{M}^{4} \mathrm{c}}$, откуда площадь барабанной перепонки для правого уха $S_{6 . n}=5,8 \cdot \frac{\omega_{p} \cdot V\left(f_{p}\right)}{c_{0}}=315,53 \mathrm{мм}^{2}$ и для левого уха $S_{6 . n}=331,89 \mathrm{мм}^{2}$, что в пять раз больше, чем значение $S_{6 . n}=64 \mathrm{mм}^{2}$, которое приводится в литературе для любого уха вообще.

Механическая масса слуховых косточек: для правого уха $m_{\text {мех }}=m_{a . \kappa} \cdot S_{\sigma . n}^{2}=67,814$ мг; для левого уха $m_{\text {мех }}=73,305$ мг .

Поскольку для обоих ушей параметр нормы $A>1$, то это свидетельствует о 
патологических изменениях в ухе.

\section{Заключение и выводы}

Были рассмотрены особенности анатомического строения евстахиевой трубы и показан метод многочастотной акустической импедансометрии для обработки результатов исследования. При всех возможных межсубьектных различий характеристик уха человека (пол, эквивалентные объемы на частотах 226, 800, 1000 Гц, резонансные частоты) параметр нормы для нормального уха $A=1$. С медицинской точки зрения фактор $A$ может служить параметром нормы, отклонения которого от единицы могут свидетельствовать о появлении физиологических или патологических изменений в ухе. Это создает перспективу использования тимпанометрии в ранней диагностике состояния среднего уха.

Литература:

1. Sahley Tony L. Basic Fundamentals in Hearing Science / Tony L. Sahley, Frank E. Musiek. - San Diego: Plural Publishing, 2014. - 686 p. ISBN: 9781597565493.

2. Doyle WJ. Physiology: introduction. Ann Otol Rhinol Laryngol. 1985;120 Suppl 94:20-1.

3. Stach Brad A. Clinical Audiology: An Introduction / Brad A. Stach. - Detroit, Michigan: Delmar, Cengage Learning, 2010. -788 p. - ISBN: 9780766862883.

4. Найда С. А. Формула середнього вуха людини в нормі. Відбиття звуку від барабанної перетинки / С. А. Найда // Акустичний вісник. -2002. -Том 5. -N 3. -C. $46-51$.

5. Найда С. А. Анамнез наследственного снижения слуха у детей / Найда С.А. // Збірник праць акустичного симпозіума "КОНСОНАНС-2009". - Київ, 2009. - C.255-260.

6. Найда С. А. Формула середнього вуха людини в нормі. Відбиття звуку від барабанної перетинки // Акустичний вісник. - 2002. - №3. - С. 46-51.

7. Найда С. А. Объективная аудиометрия на основе формулы среднего уха - новый метод исследования и дифференциальной диагностики слуха / С. А. Найда // Электроника и связь.-2004.-№23.- С.66-70.

Научный руководитель: д.т.н., проф. Найда С.А. Статья отправлена: 01.01.2017 г. (C) Дамарад А.В.

\section{ЦИТ: иа217-041}

DOI: 10.21893/2415-7538.2017-06-1-041

УДК: 628.941

Амелькина С. А., Духонькин А. Э.

ТЕХНИКА ОСВЕЩЕНИЯ ДЛЯ ДИНАМИЧЕСКИХ ПРОЕКТОВ НАРУЖНОГО АРХИТЕКТУРНОГО ОСВЕЩЕНИЯ

ФГБОУ ВО «Наииональный исследовательский МГУ им. Н. П. Огарева», г. Саранск, ул. Б. Хмельниикого, 39 